Authors' Contribution: A - Study Design B - Data Collection C - Statistical Analysis D - Data Interpretation E - Manuscript Preparation $\mathrm{F}$ - Literature Search G - Funds Collection

\section{Underweight, overweight and obesity in boys and girls at the age of 7-18 years from the Podlaskie Province (Poland) in the years 1986 and 2006}

\author{
Jerzy Saczuk ABCDEFG, Agnieszka Wasiluk ${ }^{\text {BCDEF }}$ \\ Jozef Pilsudski University of Physical Education in Warsaw, Poland \\ Faculty of Physical Education and Sport in BialaPodlaska, Poland \\ Department of Anthropology and Anthropomotorics
}

Key words: BMI, girls, boys, secular trends

\begin{abstract}
Background: The objective of this study was to determine changes in the group size of girls and boys with proper BMI values and their peers with underweight, overweight and obesity in a twenty-year time span.

Material/Methods: In 1985 and 1986,20,353 boys and girls were examined, and 20 years later, 10,705 students. Measurements of body height and body mass were taken, which enabled calculating values of the Body Mass Index (BMI). The statistical significance of differences between mean values obtained in 1986 and 2006 was verified with Student's ttest for independent variables. The statistical significance of differences between the number of girls and boys classified to each group in respect of the whole group surveyed in 1986 and 2006 was determined with the $X^{2}$ test.

Results: The greatest generation changes in the mass-to-height proportions were noted in the youngest children from the Podlaskie Province. It was higher by $1.66 \%$ in pupils with $2^{\text {nd }}$ degree underweight, and higher by $4.79 \%$ and $1.29 \%$ in pupils with overweight and obesity, respectively, while it was lower by $10.11 \%$ among boys with a normal $B M I$ value. In girls the percentage with normal BMI values was observed to decrease by $8.95 \%$, whereas among girls with overweight - to increase by $4.85 \%$.

Conclusions: The results may suggest that a greater percentage of the young generation will be characterized by improper mass-to-height proportions.
\end{abstract}

Word count: 2,992

Tables: $4 \quad$ Received: October 2013

Figures: 0

Accepted: October 2014

References: 22

Published: December 2014

Corresponding author:

Ph.D. AgnieszkaWasiluk

Faculty of Physical Education and Sport

ul. Akademicka 2, 21-500 Biala Podlaska

Phone: +48833428741

E-mail: agnieszka.wasiluk@awf-bp.edu.pl 


\section{Introduction}

Civilization advance progressingin many countries of Europe and the world contributes to lifestyle changes in entire societies. Achievements of human thought and their materialization are accompanied by numerous adverse effects, the most severe of which includes reduced physical activity which, in consequence, increases the risk of overweight and obesity development [1, 2]. Such a lifestyle results, among others, in an increased number of children with overweight and excessive body adiposity observed in recent two decades especially in highly-developed countries $[3,4,5,6]$. It is very often emphasized that obesity is the cause of many health disorders including: ischemic heart disease, hypertension, type 2 diabetes, colon cancers, prostate cancer, etc. $[7,8,9]$. In contrast, body mass deficiency remains in a strict correlation with inflammatory lesions of bronchi and lungs, asthma, improper functioning of the digestive system, and emotional disorders $[10,11]$.

The last twenty years in Poland have been aperiod of abrupt socio-economic changes and transformations. In this period a new class of wealthy people has emerged, but on the other hand a considerable part of the group has impoverished as a result of closing downof many work places and an increasing unemployment rate. The intensifying disproportions in the economic status of the Polish society were accompanied by discernible differences in the nutritional status of children and adolescents. This problem is observed in regions of the country with higher economic indices and is beginning to be noticeable in the regions with a lower rate of development $[12,13]$.

It seems interesting, therefore, to determine the rate of changes in somatic traits of adolescents inhabiting poorly-developed regions of the country. Hence, the objective of this study was to determine changes taking placewithin twenty years in the group of children and adolescents from the Podlaskie Province characterized by proper body mass to body height proportions and their peers with underweight, overweight and obesity.

\section{Material and methods}

In 1985 and1986 research was undertaken within the Key Issue 10.7, amongst children and adolescents inhabiting areas of the then Provinces: Suwalskie, Białostockie and Łomżyńskie. After administrative transformation of the country, beginning from year 1998 the aforementioned areas have become part of the Podlaskie Province. Based on the list of educational centers received from Education Offices, 120 schools were selected for the study considering the settlement structure in these regions and trying to maintain a balance in the number of schools from the former Provinces. Results of observations of 20,353 girls and boys at the age of 7-18 years, including 13,034 inhabitants of urban areas and 7,319 inhabitants of rural areas, were selected for this study from the collected material.

Observations were repeated in the same schools in 2005 and 2006, within statutory tasks of the Academy of Physical Education in Warsaw (D.S 45). This time, the surveys covered results of 10,705 pupils at the age of 7-18, including 7,021 and 3,684 inhabitants of urban and rural areas, respectively. The number of girls and boys at both stages of observations, considering their calendar age and place of residence, was presented in Table 1.

The lower number of schoolboys and schoolgirls at the second stage of the study was due to an educational reform initiated in 1993, as a result of which many small schools were closed down whereas part of the other schools was re-organized, which hindered the observations.

The survey was conducted following principles of the Helsinki Declaration and was approved by the Senate Ethical Commission acting at the Academy of Physical Education in Warsaw. A questionnaire was used to collect data on the respondents'date of birth and social conditions.

Anthropometric measurements were taken according to standard anthropometric techniques (IBP). Body height and body mass values achieved served to calculate the body mass index (BMI), defined as body mass $(\mathrm{kg})$ of an individual divided by the square of their height $(\mathrm{m})$. The obtained BMI values enabled selecting children with: $3^{\text {rd }}$ degree underweight $(\mathrm{gr} . \mathrm{l}), 2^{\text {nd }}$ degree underweight (gr. II), $1^{\text {st }}$ degree underweight (gr. III), normal BMI (gr. IV), overweight (gr. V), and obesity (gr. VI). The range of the norm was determined by subtracting all individuals with underweight, overweight and obesity from the whole examined group. The children were classified to the above groups fol- 
lowing recommendations of the Obesity Task Force based on boundary values elaborated by Cole et al. $[14,15]$. The numbers of children in particular groups were then used to compute the percentage of girls and boys with underweight, overweight and obesity in the entire material and in particular places of residence (rural, urban areas) in groups considering stages of education (7-9 years of age - integrated education; 10-12 years - primary school; 13-15 years - junior high school; 16-18 years - senior high school). Arithmetic means and standard deviations were calculated for BMI values in groups, considering the respondents'calendar age. The statistical significance of differences between mean values obtained in 1986 and 2006 was verified with Student's t-test for independent variables. The statistical significance of differences between the number of children classified to each groups in relation to the whole group surveyed in 1986 and 2006 was determined using $X^{2}$ test.

Tab. 1. Number of surveyed girls and boys from the Podlaskie Province

\begin{tabular}{|c|c|c|c|c|}
\hline Age in years & Year & Total & Rural & Urban \\
\hline & & Boys & & \\
\hline \multirow{2}{*}{$7-18$ years } & 1986 & 9927 & 3522 & 6405 \\
\hline & 2006 & 5642 & 2021 & 3621 \\
\hline \multirow{2}{*}{$7-9$ years } & 1986 & 2282 & 649 & 1633 \\
\hline & 2006 & 1599 & 292 & 1267 \\
\hline \multirow{2}{*}{$10-12$ years } & 1986 & 3044 & 996 & 2048 \\
\hline & 2006 & 1098 & 697 & 401 \\
\hline \multirow{2}{*}{$13-15$ years } & 1986 & 2610 & 946 & 1664 \\
\hline & 2006 & 1460 & 700 & 760 \\
\hline \multirow{2}{*}{$16-18$ years } & 1986 & 1991 & 931 & 1060 \\
\hline & 2006 & 1525 & 628 & 897 \\
\hline \multicolumn{5}{|c|}{ Girls } \\
\hline \multirow{2}{*}{$7-18$ years } & 1986 & 10426 & 3797 & 6629 \\
\hline & 2006 & 5063 & 1663 & 3400 \\
\hline \multirow{2}{*}{$7-9$ years } & 1986 & 2218 & 726 & 1492 \\
\hline & 2006 & 1013 & 149 & 864 \\
\hline \multirow{2}{*}{$10-12$ years } & 1986 & 3287 & 1109 & 2178 \\
\hline & 2006 & 979 & 414 & 565 \\
\hline \multirow{2}{*}{$13-15$ years } & 1986 & 2842 & 940 & 1902 \\
\hline & 2006 & 1128 & 397 & 731 \\
\hline \multirow{2}{*}{$16-18$ years } & 1986 & 2079 & 1022 & 1057 \\
\hline & 2006 & 1943 & 703 & 1240 \\
\hline
\end{tabular}

\section{Results}

In the analyzed twenty-year period, a significant decrease in the BMI value average was observed only in the group of the oldest girls. In the remaining groups selected in terms of both gender and calendar age, a significant increase was noted in the relative body mass. Girls from junior high school, in the case of whom the described differences were small, were an exception, which was confirmed by results of Student's t-test (Table 2).

From 1986 to 2006, a significant decrease was noted in the percentage of boys with proper BMI values (by $4.64 \%$ ) and those with $1^{\text {st }}$ degree underweight (by $2.90 \%$ ), whereas an increase by $6.49 \%$ was determined in the percentage of pupils with overweight. Greater changes were observed in inhabitants of cities and smaller ones in those originating from rural areas (Table 3 ). 
Table 2. BMI values of girls and boys from the Podlaskie Province in the years 1986 and 2006

\begin{tabular}{|c|c|c|c|c|c|c|c|c|c|c|}
\hline \multicolumn{4}{|c|}{ Boys } & \multirow{3}{*}{$\begin{array}{c}\text { Value } \\
\text { of Student's } \\
\text { t-test }\end{array}$} & \multirow{3}{*}{$\begin{array}{c}\text { Age in } \\
\text { years }\end{array}$} & \multicolumn{4}{|c|}{ Girls } & \multirow{3}{*}{$\begin{array}{c}\text { Value } \\
\text { of Student's } \\
\text { t-test }\end{array}$} \\
\hline \multicolumn{2}{|c|}{1986} & \multicolumn{2}{|c|}{2006} & & & \multicolumn{2}{|c|}{1986} & \multicolumn{2}{|c|}{2006} & \\
\hline $\bar{x}$ & SD & $\bar{x}$ & $\mathrm{SD}$ & & & $\bar{x}$ & SD & $\bar{x}$ & SD & \\
\hline 16.04 & 1.67 & 16.33 & 2.03 & $2.786^{*}$ & 7 & 16.64 & 2.26 & 16.95 & 2.25 & $2.012^{*}$ \\
\hline 16.38 & 1.67 & 16.59 & 1.78 & $2.112^{*}$ & 8 & 16.50 & 1.71 & 16.81 & 2.08 & $2.718^{*}$ \\
\hline 17.15 & 1.65 & 17.39 & 2.32 & $2.224^{*}$ & 9 & 16.89 & 1.64 & 17.19 & 2.34 & $2.539^{*}$ \\
\hline 17.2 & 1.94 & 17.65 & 2.11 & $5.014^{*}$ & 10 & 17.0 & 1.96 & 17.23 & 2.43 & $2.249^{*}$ \\
\hline 17.71 & 1.96 & 17.93 & 2.07 & $2.557^{*}$ & 11 & 17.38 & 2.08 & 17.73 & 2.30 & $3.415^{*}$ \\
\hline 17.63 & 2.11 & 18.5 & 2.17 & $9.572^{*}$ & 12 & 17.8 & 2.06 & 18.02 & 2.50 & $1.984^{*}$ \\
\hline 18.59 & 1.78 & 19.64 & 2.09 & $11.620^{*}$ & 13 & 18.88 & 2.09 & 19.03 & 2.33 & 1.318 \\
\hline 19.35 & 1.81 & 20.36 & 2.03 & $11.150^{*}$ & 14 & 19.62 & 1.86 & 19.51 & 2.01 & 1.046 \\
\hline 20.26 & 1.58 & 20.83 & 2.04 & $6.677^{*}$ & 15 & 20.49 & 2.08 & 20.65 & 1.93 & 1.661 \\
\hline 21.52 & 1.77 & 21.8 & 2.16 & $2.513^{*}$ & 16 & 20.92 & 2.73 & 20.19 & 1.76 & $6.354^{*}$ \\
\hline 21.37 & 1.69 & 22.3 & 1.9 & $9.188^{*}$ & 17 & 22.01 & 1.88 & 20.97 & 1.74 & $10.519^{*}$ \\
\hline 21.8 & 2.22 & 22.48 & 1.67 & $6.472^{*}$ & 18 & 21.83 & 1.81 & 20.39 & 1.70 & $14.609^{*}$ \\
\hline
\end{tabular}

*statistically significant differences at the level of $p \leq 0.05$

Table 3. Percentage of boys and girls in groups with normal BMI, underweight, overweight and obesity considering the place of residence

\begin{tabular}{|c|c|c|c|c|c|c|}
\hline \multirow{2}{*}{ BMI group } & \multicolumn{3}{|c|}{ All boys } & \multicolumn{3}{|c|}{ All girls } \\
\hline & 1986 & 2006 & test $X^{2}$ & 1986 & 2006 & test $X^{2}$ \\
\hline $3^{\text {rd }}$ underweight & 0.82 & 0.94 & 0.624 & 1.06 & 1.68 & $9.581^{*}$ \\
\hline $2^{\text {nd }}$ underweight & 1.19 & 1.60 & $4.286^{*}$ & 2.40 & 2.45 & 0.036 \\
\hline 1st underweight & 8.57 & 5.67 & $39.197^{*}$ & 11.69 & 11.28 & 0.455 \\
\hline normal BMI & 80.61 & 75.97 & $5.535^{*}$ & 75.78 & 75.67 & 0.003 \\
\hline overweight & 7.51 & 14.00 & $133.408^{*}$ & 7.97 & 8.12 & 0.085 \\
\hline obesity & 1.30 & 1.83 & $6.407^{*}$ & 1.09 & 0.81 & 2.816 \\
\hline BMI group & \multicolumn{3}{|c|}{ Urban boys } & \multicolumn{3}{|c|}{ Urban girls } \\
\hline $3^{\text {rd }}$ underweight & 1.13 & 1.14 & 2.470 & 1.03 & 1.94 & $13.174^{*}$ \\
\hline $2^{\text {nd }}$ underweight & 2.13 & 2.65 & 2.881 & 2.55 & 2.35 & 0.344 \\
\hline $1^{\text {st }}$ underweight & 10.75 & 11.37 & $15.416^{*}$ & 12.23 & 11.24 & 1.702 \\
\hline normal BMI & 77.51 & 76.55 & $5.982^{*}$ & 74.79 & 75.24 & 0.034 \\
\hline overweight & 7.87 & 7.70 & $9.997^{*}$ & 8.03 & 8.32 & 0.226 \\
\hline obesity & 0.61 & 0.60 & 2.627 & 1.37 & 0.91 & $4.074^{*}$ \\
\hline BMI group & \multicolumn{3}{|c|}{ Rural boys } & \multicolumn{3}{|c|}{ Rural girls } \\
\hline $3^{\text {rd }}$ underweight & 0.65 & 0.40 & 1.593 & 0.91 & 1.24 & 0.001 \\
\hline $2^{\text {nd }}$ underweight & 1.11 & 1.48 & 1.415 & 1.23 & 1.66 & 1.262 \\
\hline 1st underweight & 7.89 & 4.06 & $29.501^{*}$ & 8.95 & 6.57 & 0.363 \\
\hline normal BMI & 81.94 & 79.61 & 0.476 & 79.88 & 73.93 & 0.078 \\
\hline overweight & 7.41 & 12.77 & $34.523^{*}$ & 7.57 & 14.69 & 0.043 \\
\hline obesity & 0.99 & 1.68 & $4.654^{*}$ & 1.47 & 1.91 & 0.000 \\
\hline
\end{tabular}

*statistically significant differences at the level of $p \leq 0.05$ 
It ought to be emphasized that in data for the whole surveyed group a statistically significant increase was noted in the percentage of boys with $2^{\text {nd }}$ degree underweight, which was not observed in the groups selected based on the place of residence. Less significant generation changes were observed in girls. Differences in groups between stages of the study did not exceed $1.00 \%$. A statistically significant increase was only reported in the percentage of girls with $3^{\text {rd }}$ degree underweight. No significant differences were determined in the remaining groups selected based on BMI values. The analysis of environmental differences showed that only the urban group was characterized by an increase in the percentage of girls with $3^{\text {rd }}$ degree underweight and a decrease in the percentage of obese girls only in the case of urban respondents.

The above-described generation changes were not identical in all groups of calendar age (Table 4).

Table 4. Percentage of boys and girls in groups with normal BMI, underweight, overweight and obesity considering the stage of education

\begin{tabular}{|c|c|c|c|c|c|c|c|}
\hline \multirow{2}{*}{ Age } & \multirow{2}{*}{ BMl } & \multicolumn{3}{|c|}{ Boys } & \multicolumn{3}{|c|}{ Girls } \\
\hline & & 1986 & 2006 & test $X^{2}$ & 1986 & 2006 & test $x^{2}$ \\
\hline \multirow{6}{*}{$7-9$ years } & $3^{\text {rd }}$ underweight & 1.40 & 2.18 & 3.148 & 1.71 & 2.96 & $4.752^{*}$ \\
\hline & $2^{\text {nd }}$ underweight & 1.36 & 3.01 & $11.967^{*}$ & 2.16 & 2.57 & 0.471 \\
\hline & $1^{\text {st }}$ underweight & 7.32 & 8.92 & 2.717 & 11.50 & 12.83 & 0.918 \\
\hline & normal BMI & 79.71 & 69.60 & $7.233^{*}$ & 74.30 & 65.35 & $4.651^{*}$ \\
\hline & overweight & 7.84 & 12.64 & $19.352^{*}$ & 8.48 & 13.33 & $14.096^{*}$ \\
\hline & obesity & 2.37 & 3.66 & $5.079^{*}$ & 1.85 & 2.96 & $3.640^{*}$ \\
\hline \multirow{6}{*}{$10-12$ years } & $3^{\text {rd }}$ underweight & 0.72 & 0.64 & 0.085 & 1.16 & 2.66 & $9.726^{*}$ \\
\hline & $2^{\text {nd }}$ underweight & 0.92 & 1.28 & 0.946 & 2.80 & 1.74 & 3.555 \\
\hline & 1st underweight & 9.40 & 6.38 & $8.441^{*}$ & 14.45 & 10.11 & $10.007^{*}$ \\
\hline & normal BMI & 79.04 & 74.68 & 1.121 & 73.08 & 73.24 & 0.002 \\
\hline & overweight & 8.71 & 15.76 & $31.303^{*}$ & 7.30 & 11.85 & $15.777^{\star}$ \\
\hline & obesity & 1.22 & 1.28 & 0.023 & 1.22 & 0.41 & $5.774^{*}$ \\
\hline \multirow{6}{*}{$13-15$ years } & $3^{\text {rd }}$ underweight & 0.73 & 0.55 & 0.468 & 0.91 & 1.68 & $3.860^{*}$ \\
\hline & $2^{\text {nd }}$ underweight & 1.69 & 1.23 & 1.284 & 3.27 & 1.77 & $6.831^{*}$ \\
\hline & $1^{\text {st }}$ underweight & 9.81 & 5.62 & $19.541^{*}$ & 10.98 & 9.75 & 1.053 \\
\hline & normal BMI & 80.34 & 74.18 & 2.587 & 76.00 & 79.79 & 0.839 \\
\hline & overweight & 6.67 & 16.99 & $82.185^{\star}$ & 8.23 & 6.47 & 3.127 \\
\hline & obesity & 0.77 & 1.44 & $3.975^{\star}$ & 0.60 & 0.53 & 0.062 \\
\hline \multirow{6}{*}{$16-18$ years } & $3^{\text {rd }}$ underweight & 0.40 & 0.26 & 0.504 & 0.43 & 0.51 & 0.141 \\
\hline & $2^{\text {nd }}$ underweight & 0.75 & 0.72 & 0.012 & 0.82 & 3.14 & $28.875^{\star}$ \\
\hline & 1st underweight & 7.13 & 1.90 & $52.007^{\star}$ & 8.51 & 11.94 & 10.537 \\
\hline & normal BMI & 84.38 & 85.11 & 0.030 & 81.34 & 79.88 & 0.147 \\
\hline & overweight & 6.43 & 11.28 & $21.658^{*}$ & 8.13 & 4.48 & $20.220^{*}$ \\
\hline & obesity & 0.90 & 0.72 & 0.351 & 0.77 & 0.05 & $14.914^{*}$ \\
\hline
\end{tabular}

${ }^{*}$ statistically significant differences at the level of $p \leq 0.05$

The greatest number of statistically significant differences was observed in boys at the age of 7-9. This group was characterized with a higher percentage of pupils with $2^{\text {nd }}$ degree underweight (by $1.66 \%$ ), and with a higher percentage of pupils with overweight and obesity (by $4.79 \%$ and $1.29 \%$, respectively), as well as with a lowerpercentage of boys with normal BMl value (by $10.11 \%)$. In the case of boys from the Podlaska Province being at the age of 10 to 18 years, a sig- 
nificant decrease was noted in the percentage of respondents with $1^{\text {st }}$ degree underweight and an increase in the percentage of those with overweight.

The group of girls was characterized by a significant increase in the percentage of respondents with the greatest body mass deficiency. In the analyzed groups, apart from the oldest girls, the reported differences were significantand the greatest differences were determined in the age category of $10-12$ years (1.50\%). In addition, since 1986 till2006, in the age category of 7-9 years, the percentage of girls with normal BMI values was observed to decrease by $8.95 \%$, whereas that of girls with overweight - to increase by $4.85 \%$. In the case of girls from primary schools, the percentage of pupils with $1^{\text {st }}$ degree underweight decreased by $4.34 \%$ and that of pupils with overweight increased by $4.55 \%$. In the group of girls attending junior high schools, the percentage of girls with $2^{\text {nd }}$ degree underweight decreased by $1.50 \%$ and that of girls with normal BMI increased by $3.78 \%$. In turn, in the age category of 16-18, an increase was observed in the percentage of girls with $2^{\text {nd }}$ (by $2.32 \%$ ) and $1^{\text {st }}$ (by $3.43 \%$ ) degree of underweight, whereas percentages of girls with overweight and obesity were observed to decrease (by $3.64 \%$ and $0.72 \%$, respectively). The other differences were negligible and statistically insignificant.

\section{Discussion}

The economic crisis of the 1970 s and 1980 s as well as socio-economic transformations taking place in Poland since 1989 and their differentiated pace in particular regions have affected the extent of secular trends in somatic traits. Based on surveys conducted in that period with adolescents from the whole country, the values of somatic traits were observed to increase, with the increase varying depending on both the period and area of observations. The environment the girls and boys were growing up in was confirmed to still modify their developmental process to a various extent in different regions of Poland [16, 17, 18]. Higher body height values and a significant increase in body mass were also determined in girls and boys from eastern Poland [19]. Hence, it is obvious that the research conducted in the Podlaskie Province in 2006 revealed higher BMI values compared to the mean values achieved in 1986.

Contemporarily, a declining tendency is being observed globally in the number of children and adolescents with body mass deficiency and a growing one in the number of individuals with excessive body mass. Such a trend may be noticed in both developing countries as well as in the highly-developed ones $[3,5,6]$. Such changes are more noticeable amongst inhabitants of urban than rural areas. Such conclusions were formulated by Wang et al. [20] based on research on schoolgirls and schoolboys from Brazil, China, Russia and the USA. They were seeking reasons for these changes in differences in nutritional habits and reduced physical activity. The observed global trend of the increasing number of persons with overweight and obesity is also slowly spreading in Poland. Currently, Polish adolescents, including these from the Podlaskie Province, are characterized by the lowest overweight and obesity rates compared to results noted for their peers in the European Union, the USA or Canada [21, 22]. However, in the years 1995-2005 the frequency of overweight and obesity occurrence in the Polish school adolescents increased by $2.4 \%$ and $1.5 \%$ in boys and by $2.0 \%$ and $2.0 \%$ in girls [21]. In the Podlaskie Province from 1986 to 2006 the tendency for a decreasing number of children and adolescents with body mass deficiency and for an increasing number of individuals with body mass excess was observed only in the case of boys, with greater differences noted in boys from urban than from rural areas. The causes of differences in BMI values over the twenty-year period ought to be searched for in changes in the socio-economic conditions of the country, as described in the Introduction section. The picture of the described secular trends is undoubtedly influenced by the place of residence. The problem of unemployment affected inhabitants of cities to a greater extent, because in rural areas it was easier to provide for the family at small farms. In addition, rural children more frequently participated in work at the farm, which could be reflected in their higher physical activity. Such tangible generation changes were not observed in the case of girls who are less eco-sensitive than boys. Alarming is an increasing percentage of schoolgirls with a significant body mass deficiency observed especially in the girls living in cities, which has not been observed in many countries. It should also be emphasized that increasing silhouette slenderness (reflected in decreasing BMI 
values) and decreasing percentages of girls with overweight and obesity were observed in the oldest age category of girls. The reasons behind these changes should be looked for in the consciousness of the surveyed schoolgirls, namely in their lifestyle, nutrition etc. Of great significance is also contemporary fashion and strive for a slim silhouette. In this case, worthy of notice is that in 1986 the girls from eastern provinces of Poland were characterized by significantly higher body adiposity compared to ordinary Polish girls and girls from large cities [19]; therefore, the observed tendency of changes may be acknowledged as positive. The greatest number of statistically significant differences was noted in the youngest children from the Podlaskie Province. It may suggest that a greater percentage of the young generation will be characterized by improper mass-to-height proportions.

Confirmation of these observations requires more extensive social research.

\section{Conclusions}

The analysis of the study material enables formulating the following conclusions and observations:

1. Effects of civic transformations observed worldwide are beginning to enter areas of the Podlaskie Province, which was reflected in increasing BMI values and increasing percentages of boys and young girls with excessive body mass.

2. Alarming is the increased percentage of schoolgirls with significant body mass deficiency, which may indicate their malnutrition and may trigger inflammatory states of bronchi and lungs, asthma, improper functioning of the digestive system and emotional disorders.

3. The greatest generation changes in the mass-to-height proportions were noted in the youngest children from the Podlaskie Province. It may suggest that a greater percentage of the young generation will be characterized by improper mass-to-height proportions. Therefore, classes of physical education should be held by teachers of physical education and not by teachers of integrated education.

\section{References}

1. Datar A, Nicosia N, Shier V. Maternal work and children's diet, activity, and obesity. Soc Sci Med. 2014;107:196-204.

2. Nawab T, Khan Z, Khan IM, Ansari MA. Influence of behavioral determinants on the prevalence of overweight and obesity among school going adolescents of Aligarh. Indian J Public Health. 2014;2:121-124.

3. Janssen I, Shields M, Craig CL, Tremblay MS. Changes in the obesity phenotype within Canadian children and adults, 1981 to 2007-2009. Obesity. 2012;4:916-919.

4. Abela S, Bagnasco A, Arpesella M, Vandoni M, Sasso L. Childhood obesity: an observational study. J Clin Nurs. 2014;19-20:2990-2992.

5. Güngör NK. Overweight and obesity in children and adolescents. J Clin Res Pediatr Endocrinol. 2014;3:129-143.

6. Savva SC, Kourides YA, Hadjigeorgiou C, Tornaritis MJ. Overweight and obesity prevalence and trends in children and adolescents in Cyprus 2000-2010. Obes Res Clin Pract. 2014;5:426-434.

7. Kopelman P. Health risks associated with overweight and obesity. Obesity. 2007;s1: 13-17.

8. Bray GA. Medical Consequences of Obesity. J Clin Endocrinol Metab. 2014;6:2583-2589.

9. Scarpa M, Ruffolo C, Erroi $F$, et al. Obesity is a risk factor for multifocal disease and recurrence after colorectal cancer surgery: A case-control study. Anticancer Res. 2014;10:5735-5741.

10. Wiltink J, Michal M, Wild PS, et al. Associations between depression and different measures of obesity (BMI, WC, WHtR, WHR). BMC Psychiatry. 2013;13:223.

11. Raj D, Kabra SK, Lodha R. Childhood Obesity and Risk of Allergy or Asthma. Immunol Allergy Clin North Am. 2014;4:753-765.

12. Chrzanowska M, Suder A. The extent of overweight index in children and adolescents from Cracow, Poland (1971-2000). HOMO. 2010;6:453-458.

13. Wasiluk A, Saczuk J, Zalech M. Underweight, overweight and obesity in girls at the age of 7-19 years from the Lubelskie Province in the years 1986-2006. Pediatric Endocrinology, Diabetes and Metabolism. 2013;1:11-17.

14. Cole TJ, Bellizzi MC, Flegal KM, Dietz WH. Establishing a standard definition for child overweight and obesity worldwide: international survey. BMJ 2000;320:1240-1243. 
15. Cole TJ, Flegal KM, Nicholls D, Jackson AA. Body mass index cut offs to define thinness in children and adolescents: international survey. BMJ. 2007; 335:194-197.

16. Przeweda R, Dobosz J. Growth and physical fitness of Polish youths. Warszawa: AWF; 2005.

17. Laska-Mierzejewska T, Olszewska E. Anthropological assessment of changes in living conditions of the rural population in Poland in the period 1967-2001. Ann Hum Biol. 2007, 3:362-376.

18. Bielicki T, Szklarska A, Koziel S, Ulijaszek SJ. Changing patterns of social variation in stature in Poland: effects of transition from a command economy to the free-market system? J Biosoc Sci. 2005;37:427434.

19. Saczuk J, Wasiluk $A$. Changes in the somatic and fitness variables in girls over two decades. Biomedical Human Kinetics. 2010;2:102-105.

20. Wang Y, Monteiro C, Popkin BM. Trends of obesity and underweight in older children and adolescents in the United States, Brazil, China, and Russia. Am J Clin Nutr. 2002;75:971-977.

21. Oblacinska A, Jodkowska M. Otyłosc u polskich nastolatków. Epidemiologia, styl życia, samopoczucie [Obesity among Polish teenagers. Epidemiology, lifestyle, well-being]. Warszawa: Instytut Matki i Dziecka; 2007. Polish

22. Tokmakidis A, Christodulos D, Savvas P. Fitness levels of Greek primary schoolchildren in relationship to overweight and obesity. Eur J Pediatr. 2006;165:867-874. 